\title{
Health guides for unattended births and aftercare in New Zealand and Australia, 1900-1950.
}

Pamela Wood ${ }^{A}, B$ PhD, RN • Jan Jones ${ }^{C}$ BN, Grad Dip Mid, MCM

\author{
${ }^{\text {A Corresponding }}$ \\ Author: pamela. \\ wood@federation. \\ $\underline{\text { edu.au }}$ \\ ${ }^{\mathrm{B}}$ Faculty of Health, \\ Federation University \\ Australia \\ C School of \\ Nursing, Midwifery \\ \& Healthcare, \\ Federation University \\ Australia
}

\begin{abstract}
Background: In the early twentieth century, most women in Australia and New Zealand gave birth at home. As in colonial times, women living in the isolated New Zealand backblocks or Australian bush without access to a midwife, nurse or doctor, or women in towns who could not afford their service, gave birth with only a neighbouring woman, husband or older child to help. Most households had a domestic health guide as a source of health information and support in caring for themselves and others. This guide might therefore be the only assistance available to women and their lay attendants during childbirth.
\end{abstract}

Aim: This research aimed to identify the information domestic health guides provided on childbirth, particularly if addressed to a person assisting the woman in the absence of a midwife, nurse or doctor, and to compare it with information midwives were expected to know.

Methods: Using historical methodology, the researchers analysed the childbirth information in a range of domestic health guides available in Australia and New Zealand, 1900-1950. The information was also compared with midwifery textbooks and considered within the context of the increasing professionalisation of midwifery to discover how it reflected boundaries between lay and professional knowledge and practice.

Findings: Some domestic health guides provided as detailed information as midwifery texts but without their scientific rationale that was a mark of professional knowledge and practice.

Conclusion: By providing clear information, domestic health guides could have been a significant part of the culture of self-reliance and mutual aid, and of the cultures of health in both rural and urban environments in New Zealand and Australia in this time period.

Key words: health guides; home birth; historical research; history of midwifery

\section{INTRODUCTION}

In the early twentieth century, the home was the primary setting for giving birth and for nursing the sick. The family member caring for someone in the home looked to their domestic health guide for essential information (Wood, 2013). In colonial Australia, guides written by doctors and lay people in Britain and Australia advised intending colonists and settlers on matters of health and first aid (Pearn, 2012). Many early guides were therefore written specifically for a European settler readership. Later guides also had a European focus, as evidenced by their examples and illustrations. Their use by indigenous populations is unknown.

Brookes (2003) noted that in early twentieth-century New Zealand, written sources gradually eroded the mother's role "as the prime source of information about health and bodily knowledge" (p.298). European people living in the isolated Australian bush or New Zealand backblocks, however, had always relied on their domestic health guide and, as Brookes indicated, this continued into the twentieth century. Even in 1927, Alice Basten of the Auckland Mayoress's War Memorial Library League hoped people would help her address the "very pathetic appeals from the backblocks for medical works suitable for the instruction of housewives, and also for books, etc., on the care and nursing of babies" ('Books Wanted', 1927, p.7). The possible use of domestic health guides by indigenous communities was beyond the scope of this study. For the pregnant woman, domestic health guides gave information about pregnancy, childbirth and the care of infants. The guides helped them prepare for the forthcoming birth. As the 1900-1950 period progressed, legislative changes required that birth attendants be registered midwives and cultural changes led to a gradual shift to giving birth in hospital (Mein Smith, 1986). However, the untrained handywoman or neighbour might be the only attendant available to a woman if she could not afford to engage a registered midwife or if the midwife was suddenly unable to attend. Women living in isolated rural communities might not have access to midwifery services, so in many cases the husband, older child or neighbour might be the only person able to support the woman during birth.

Without a professional or experienced attendant, women and their supporters could turn to a domestic health guide for instruction. The writers of many guides anticipated this situation and provided a section specifically addressing a lay attendant. Analysing and interpreting this material therefore enables us to understand a significant aspect of maternity care at this time and the boundary, if any, between lay and professional knowledge and practice in a context of the increasing professionalisation of midwifery (e.g. Grehan, 2004). 


\section{AIM}

The aim of this research was therefore to examine the kind of information about childbirth provided in domestic health guides, and to interpret the findings by comparing them with information contained in midwifery textbooks.

\section{METHOD}

Historical research may describe the historiography of the topic - what historians have already written about the subject and how they have approached it. This relates most closely to the literature review in reports of other research. In this case, however, no previous studies have examined this subject, so a historiography is not possible. In addition, historical research is not normally positioned within a conceptual or theoretical framework but considers its interpretation in relation to relevant contexts. In this case, the relevant contexts are the self-help and mutual aid expected in the bush (Raftery, 1999) and the "cultures of health" in early New Zealand and Australia (Coleborne \& Godtschalk, 2013, p.404). Consideration of these contexts helps us to understand the breadth of health information and support available beyond professions such as midwifery.

\section{Research design}

Historical methodology has a widely accepted process (Tosh, 2015) and has been described for investigating nursing and midwifery history (Lewenson \& Herrmann, 2007; Mortimer \& McGann, 2005; Wood, 2011). It is the selection and analysis of historical primary sources - material created within the time period being considered - and their interpretation in the context of the time.

\section{Some of the selected domestic health guides were written by doctors in Britain or the USA but others were produced in Australia.}

For this historical study, a range of domestic health guides available in Australia and New Zealand at different times for the period 1900-1950 was selected as the historical primary source material. Sections on "childbirth" or "labour" were analysed to identify the key features of the information provided to women to prepare them for childbirth or to instruct their lay attendants who were helping them at home in the absence of a midwife or doctor. This analysis included firstly examining the way the information was structured (for example, as a general description with little detail, or in clear sections relating to preparation for birth, stages of labour and aftercare) and secondly reviewing the level and nature of information provided (for example, brief reassurances with little information, or specific detailed instructions for a lay attendant). The findings were interpreted in the context of professional midwifery education in this time period by comparing them with information in midwifery textbooks, to determine any boundaries between lay and professional knowledge and practice. They were also considered in relation to secondary sources (literature written in the present day about the past) addressing midwifery education, regulation and practice and the social context of the time period.

\section{Domestic health guides}

Ten domestic health guides, as well as later editions for five of these guides, were selected for analysis. These were all accessed in Australia or New Zealand. Some did not specify the date of publication so this was gauged by considering other information, such as the clothing, hair styles and furnishings in photographs, the style of illustrations, mention of copyright legislation or daterelated treatments such as penicillin. Consulting holdings in the
Wellcome Library in London, which is the major international collection of historical medical texts, was also helpful in identifying likely publication dates. Successive publications by the same author were not always noted by a separate edition number.

\section{FINDINGS}

Some of the selected domestic health guides were written by doctors in Britain or the USA but others were produced in Australia. One guide written for the Australian and New Zealand setting was by Philip Muskett (1903), an Australian doctor. The second of his two large, heavy volumes contained detailed information on childbirth and the first volume had a "Profusely Pictured, Private and Separate, Section for Women" (title page), a booklet tucked into the rear cover.

As with this guide, others presented topics alphabetically, with labour appearing between knock-knee and laburnum poisoning, or childbirth between chilblains and children. From 1899, Edward Kirk (1904, 1930), a Scottish minister, updated his medical father's very popular books but these gave little advice on childbirth. The guide by George Black (n.d. c1910, n.d. c1940), a Scottish doctor, recognised that especially in rural places a baby could be born before professional help arrived. He therefore laid down "a few plain rules for the guidance of those who may at any time be thus awkwardly situated" (p.123). This book was later edited by Charles Hatrick (n.d. c1945), an English doctor, who reiterated the advice. George Somerville's (n.d. c1920s) health encyclopaedia and The Illustrated Family Doctor (by a General Practitioner) (1935), the final alphabetical guides in this study, gave extensive practical information.

Other domestic health guides grouped topics in sections. The Signs Publishing Company in Victoria, Australia, produced general guides by Frederick Rossiter (1910, 1913), containing practical information about childbirth. It also published guides specifically for women. One by Scottish doctors F.C. Richards and Eulalia Richards (n.d. c1910) carried a "pocket appendix" booklet of drawings of female anatomy, the baby's head emerging, and potential complications such as uterine prolapse. A later edition produced solely by Eulalia Richards (1945) included a "manikin", technically an anatomical fugitive sheet. This was a hinged assemblage of coloured cut-outs of body organs, skeleton and musculature of (in this case) a pregnant woman's body. Cut-outs could be lifted in turn to reveal ever-deepening layers of the body's interior and the organs' relative positions. These volumes carried a specific section addressing the person attending the woman in the absence of a doctor.

\section{'emergencies are always occurring, and often the women folk who come to the assistance have no knowledge of what should be done'.}

The guide by Howard James (1923, 1929), the medical superintendent of the Warburton Sanatorium in Victoria, Australia, which was associated with the Signs Publishing Company, similarly noted that "emergencies are always occurring, and often the women folk who come to the assistance have no knowledge of what should be done". As he believed that "every woman should have some knowledge of the management of a confinement case" (p.296), he gave practical instruction but noted that the attendant "must leave everything to nature" (p.298). A London publication, The Motherhood Book (n.d. c1920s) tried 
to counter the "stray bits of information" and "unwise gossip of elders" that caused women's apprehension or "terrible dread" (p.106), by providing clear information and encouragement.

\section{Advice on labour}

The domestic health guide could be an invaluable source of information for the woman and her lay supporter, covering preparation for birth, each stage of labour and aftercare.

\section{Preparation for birth}

As most women were expecting to give birth at home, many of the guides provided considerable detail about the necessary preparations, including the room and equipment. A separate room was at this time to be used (perhaps idealistically) only for the birth and lying-in period. It needed a "thorough turn out" (Motherhood Book, n.d. c1920s, p.103), including sweeping the chimney, taking up and beating the carpet, washing the floor and woodwork with soap and water and the walls with a damp cloth, and removing superfluous furniture (e.g., Illustrated Family Doctor, 1935; James, 1923, 1929; Muskett, 1903). Muskett advocated the purchase of Max Arnold's Antiseptic Accouchement Outfit and advised where it could be obtained, while Richards (1945) gave a detailed description of sterile requirements and how to sterilise items at home if the local hospital was unable to offer this service.

Absolute cleanliness was required of the "mother and those about her" (Somerville, n.d. c1920s, p.146). The attendant needed scrupulously clean hands, with nails scrubbed and hands soaked in antiseptic (e.g., Illustrated Family Doctor; Muskett, 1903). The woman needed to "thoroughly cleanse the external parts" with antiseptic soap, in a backwards direction to prevent infection being carried from the bowel to vagina (Motherhood Book, p.107). The attendant should wash "the outside of the passage, as well as the hairy parts" with lysol or carbolic solution on cotton wool or linen (Muskett, p.35).

\section{An enema and vaginal douche were generally advised in the first stage of labour together with vaginal examinations performed \\ by the doctor, or nurse if no doctor was attending.}

\section{Stages of labour}

The majority of the domestic health guides gave quite detailed information about labour and how it should be managed. Nearly all described the three stages, identifying what was happening and the types of pains the woman would be experiencing at each stage. Only Kirk (1904), Black (n.d. c1910, n.d. c1940) and Hatrick (n.d. c1945) made no mention of stages of labour, nor offered any advice about management, but focused on different issues such as anaesthetics and complications.

\section{First stage of labour}

An enema and vaginal douche were generally advised in the first stage of labour (James, 1923, 1929; Muskett, 1903; Richards, 1945; Rossiter, 1910, 1913; Somerville, n.d. c1920s) together with vaginal examinations performed by the doctor (Richards, 1945), or nurse if no doctor was attending (Muskett, 1903). A shave was only advised in two of the guides (Motherhood Book, n.d. c1920s; Richards 1945).

Most of the guides advised the woman to stay up and about in the first stage of labour, and to eat a light diet and drink as desired but avoid alcohol. Once the second stage was reached, she was to go to bed where she would remain for 7-10 days following the birth. Keeping the bladder empty during labour was important to Rossiter (1910, 1913) and Richards (1945) and advised in the Motherhood Book (n.d. c1920s). Pain relief was infrequently addressed and often seen as the domain of the doctor, who might administer an anaesthetic (James, 1923, 1929; Kirk, 1904, 1930; Somerville, n.d. c1920s; Richards, 1945). Richards and Richards (n.d. c1910) suggested the use of hot packs and The Motherhood Book recommended that the nurse rub the woman's back or legs to relieve cramps. Rossiter had a list of 11 instructions for the obstetrical nurse who would be helping him, including making the bed early, attending to hygiene and elimination, and positioning the woman. The final instruction, "Do not get excited" (p.458), risked irking rather than amusing professional nurses.

\section{Most guides cautioned against pulling on the cord, and advocated waiting for pulsations to stop before tying it off.}

\section{Second stage of labour}

Second stage of labour was identified by the beginning of the bearing down pains and rupture of the membranes. Only Muskett (1903) and Richards (1945) gave very detailed instructions on how to manage the birth itself but Richards noted these were only for use if the doctor was absent. Hatrick (n.d. c1945) and Muskett gave particular instructions for where the attendant should put her hands. The Motherhood Book (n.d. c1920s) suggested strategies for the nurse to help relieve the woman's pain and indicated the doctor would take over and administer an anaesthetic when birth was imminent.

Most guides suggested the woman should be in the left lateral position with her buttocks near the edge of the bed for the birth but Somerville (n.d. c1920s) advised that the woman could lie down or be upright, whichever she preferred. Muskett (1903) and Richards (1945) gave instructions for controlling the speed with which the head was born. Black (n.d. c1910, n.d. c1940), Hatrick (n.d. c1945), Richards and Muskett advised subsequently checking for a cord around the neck.

\section{Third stage of labour}

Muskett (1903) gave detailed instructions on how to manage the third stage of labour including advice if the placenta failed to deliver within 20 minutes. A number of guides were concerned with preventing haemorrhage. They advised grasping the womb at the time of birth and holding it until the doctor arrived (Black n.d c1910, n.d. c1940; Hatrick, n.d. c1945; Motherhood Book, n.d. c1920s; Muskett, 1903; Richards, 1945) or massaging the uterus (Illustrated Family Doctor, 1935; James, 1923, 1929) until the placenta was delivered. Most guides cautioned against pulling on the cord, and advocated waiting for pulsations to stop before tying it off (Motherhood Book; Richards; Richards \& Richards, n.d. c1910; Rossiter, 1910, 1913).

\section{Aftercare}

Following the birth, most guides noted the woman was to be washed and made comfortable before settling for a sleep. Only Muskett (1903) and the Illustrated Family Doctor (1935) advised putting the baby to the breast. Muskett suggested regular vaginal douches yet Richards and Richards (n.d. c1910) believed they should only be administered on a physician's orders. Aperients or enemas could be administered on day three (James, 1923, 1929; Muskett; Richards \& Richards; Rossiter, 1910, 1913) and 
a catheter could be inserted if the woman experienced difficulty voiding (James; Rossiter; Somerville, n.d. c1920s).

The most frequently mentioned postnatal problem was postpartum haemorrhage but several other complications were identified. Muskett (1903) and Richards (1945) were concerned with infection and Richards and Richards (n.d. c1910) discussed breast abscess and sub-involution of the uterus but only Somerville (n.d. c1920s) mentioned "white leg", the development of thromboembolytic disease. If a postpartum haemorrhage occurred it was to be managed by giving a hot vaginal douche (Muskett; Rossiter, 1910, 1913).

\section{DISCUSSION}

Very few changes in the information offered by the domestic health guides were evident across this 1900-1950 period. Different editions of the same guide could carry precisely the same information. The two guides at either end of the period were the most detailed (Muskett, 1903; Richards, 1945). Muskett was deliberately including detailed information as he was writing particularly for settlers in the remote, isolated areas in both Australia and New Zealand where no other help might be available. Richards, however, made no distinction about the location of her readers so it is difficult to draw any conclusion about why this guide offered more detail than those in the intervening years. It might have reflected an increasing expectation for people to take responsibility for their health. Britain, where this text was written, was moving towards a National Health System and had a strong emphasis on public health and encouraging individuals to participate in sport, eat as well as possible in a time of continuing post-war rationing and live healthily (e.g. Macdonald, 2011).

\section{Very few changes in the information offered by the domestic health guides were evident across this 1900-1950 period.}

The greatest difference is between the domestic health guides and midwifery textbooks. The education of midwives has been described for New Zealand (e.g. Gilkison, Giddings \& Smythe, 2013; Pairman, 2005) and for Australia (e.g. Grehan, 2004) but these studies did not address midwifery textbooks. Two editions of two midwifery textbooks used in New Zealand in this time period (Corkill, 1940, 1946; Jellett, 1926, 1929) were selected to compare information in the domestic health guides with material that midwives were expected to know. There was little difference in the kind of information provided by several of the domestic health guides when compared with these textbooks, although the textbooks were generally more detailed. Two areas were selected for deeper analysis and comparison - the aseptic management of labour and the management of the third stage.

In their prefaces, both Jellett (1929) and Corkill (1940) emphasised the aseptic management of labour, likening it to surgical asepsis. Both covered this issue in detail in a separate chapter. The domestic health guides also addressed the issue but to a lesser extent, focusing mostly on the cleanliness and arrangement of the room. Four guides briefly addressed the attendant's personal cleanliness (Illustrated Family Doctor, 1935; Motherhood Book, n.d. c1920s; Muskett, 1903; Somerville, n.d. c1920s). On the other hand, this was given considerable attention in the two textbooks. Nurses were to have short nails and scrupulously clean hands, and wear gowns, gloves and masks, as for a surgical operation. They were also instructed in the bacteriological basis for this. Two guides (James 1923, 1929; Somerville) briefly explained the risk of infection - blood-poisoning, puerperal sepsis or child-bed fever - and Somerville mentioned the cause as 'disease germs gaining entry to the mother's system through the womb, before, during or soon after labour' (p.146). Only one likened asepsis to surgery. "Although childbirth differs usually from a surgical operation in that it is a natural physiological process, it resembles the latter in exposing the patient to the risk of infection with microbes" (Illustrated Family Doctor, p.147).

\section{The gradual shifting of the site of birth from homes to small private hospitals run by midwives or doctors and to large public hospitals in subsequent decades did not significantly affect this mortality rate.}

There was a political reason, too, for the textbooks to emphasise asepsis. Maternal mortality had received significant attention in both Australia and New Zealand from the early 1900s when the rates were compared with other countries. Proud boasts of being modernised societies were put at risk by what were perceived as poor birth outcomes, including maternal mortality. The maternal mortality rate in the early 1900 s in New Zealand, for example, was $6 / 1000$ live births. The gradual shifting of the site of birth from homes to small private hospitals run by midwives or doctors and to large public hospitals in subsequent decades did not significantly affect this mortality rate. Any anticipated increase in safety by giving birth in hospitals did not eventuate. In fact, puerperal sepsis increased, except in the state-run St Helens hospitals (Wood \& Foureur, 2005, 2007). As a result, the Department of Health in New Zealand instituted a detailed regime for the aseptic management of birth (Mein Smith, 1986). This was reflected in the textbooks.

Most of the domestic health guides gave only brief information about the third stage of labour. Most mentioned waiting until the cord stopped pulsating before tying it off. Jellett (1929) referred to a former dispute about when to tie off the cord, clarifying that it had now been proven that waiting until the pulsations ceased resulted in "more vigorous" children who regained their original weight more rapidly (p.168). Jellett and Corkill (1940) differed in some aspects of third stage care. Jellett considered natural expulsion of the placenta a slow, "tedious process" (p.169). He advocated using the Dublin method of expressing the placenta once it had separated as it hastened the process, was "a most important mode of treatment, and a perfectly safe one" (p.170).

\section{Most of the domestic health guides gave only brief information about the third stage of labour.}

Having explained how to recognise placental separation, he advised midwives to grasp the fundus during a pain and press it down and back towards the sacrum, thus driving the placenta into the vagina where it could be gently drawn out. Corkill described a (literally) hands-off approach. The midwife should not massage the uterus. The dangers resulting from the temptation to interfere, 
he said, led some teachers to advise keeping hands away from the abdomen entirely, until separation occurred. However, there could be an advantage if the midwife merely placed a "controlling hand" to judge the condition of the uterus (p.111). In contrast, the domestic health guides recommended grasping and holding the uterus to prevent haemorrhage. Even James (1923, 1929), who had advised attendants to "leave everything to nature" (p.298), advocated massaging the uterus until the placenta was delivered.

\section{Although the guides were catering for a lay readership, they frequently included detailed information and instruction.}

Comparison of the guides and textbooks allows us to consider any boundary between lay and professional knowledge and practice. Although the guides were catering for a lay readership, they frequently included detailed information and instruction. This might suggest a blurred boundary between lay and professional spheres, as Wood (2013) noted for aspects of nursing care described by domestic health guides and nursing textbooks. The significant difference with the midwifery textbooks, however, was that they provided a rationale and scientific (including bacteriological) basis for their instructions. Professional knowledge and practice were therefore to be grounded in a clear articulation of science and reasoned argument.

The remaining problem, though, was the differentiation between midwifery and medicine. Midwifery in Australia gradually achieved professional recognition (for example, through state registration) during the early decades of this time period (Grehan, 2004). New Zealand midwifery had achieved state registration in 1904. The crux of registration was to mark a clear boundary between professional midwives and untrained handywomen. Midwifery textbooks, written by doctors, delineated the boundaries of midwives' professional knowledge. The irony was that they felt bound to provide more information than they might have wished in order to ensure the midwife could effectively assist them. Jellett (1929) described his textbook as offering information beyond the midwife's "everyday practice" for this reason. She should consequently take care that the knowledge did not "lead her to assume responsibilities which she is unable or forbidden to discharge". She should remember "her work in life is to be a good nurse and not a bad doctor" (p.vi). Midwifery textbooks, written by doctors, therefore attempted to strictly confine the midwife's role to one of support for the doctor attending the woman during childbirth. They assumed a professional hierarchy. Midwives, however, were able to practise independently and many did so, running their own "maternity homes" or hospitals, usually of two to six beds, or attending women in their homes.

\section{He believed a 'knowledge of how to conduct a confinement case should be possessed by every woman, and possibly by every man'.}

It is important to consider the place of domestic health guides within the social context of the time. Muskett's (1903) purpose in writing a guide was to provide a "vast fund of medical information" that would "occupy the position of guide and friend" to people "throughout the whole expanse of Australasia" (vol.1, p. xi). He believed a "knowledge of how to conduct a confinement case should be possessed by every woman, and possibly by every man" (p.33). Raftery (1999) described a parallel "lay tradition based on self-care and neighbourly co-operation" that ran alongside professional care (p.285). This is the context for the popularity of domestic health guides. The "volume of formal health advice that was publicly available' increased during the nineteenth century, including 'popular books and manuals of household hints and remedies (Raftery, 1999, p.286). We would argue that it continued into the twentieth century, as Brookes (2003) also noted. It was part of what Coleborne and Godtschalk (2013) described as "cultures of health", revealed in the way "communities organised informally to exchange knowledge and practical support for the purposes of health" in Australia and New Zealand (p. 404). Domestic health guides were part of the materiality of these cultures of health and provided important information to women about childbirth. A forthcoming birth created anxieties for women because of its perceived dangers. The risk of dying was widely recognised, as evidenced in women's letters, diaries and memoirs (Clarke, 2012). For women in remote areas, this anxiety about childbirth and its perceived dangers was heightened by lack of access to assistance. Specific instructions in domestic health guides would therefore have given them a degree of reassurance and practical help.

\section{CONCLUSION}

Information in domestic health guides was directed at two audiences - women who expected to have a trained attendant at the birth and those who did not. A trained attendant might be lacking because their services were not available in the woman's isolated district or because she could not afford to engage one. She therefore expected to manage with the help of a friend or relative. Sometimes the trained attendant, whether nurse or doctor, did not arrive in time. The domestic health guide could therefore be an invaluable source of information, covering preparation for birth, each stage of labour and aftercare.

\section{Information in domestic health guides was directed at two audiences - women who expected to have a trained attendant at the birth and those who did not.}

Some domestic health guides offered similar and as detailed information as midwifery textbooks at the time, but not their level of rationale and scientific basis. These features marked out the separate sphere of professional knowledge and practice. An issue for doctors was its delineation from the medical sphere. Even so, doctors were usually the writers of domestic health guides and offered lay readers considerable information to help them in times of need. This is the paradox - doctors were willing to assist women and lay attendants by providing information but were anxious about midwives' potentially inflated sense of responsibility and sphere of practice. This was addressed by stressing in both domestic health guides and midwifery textbooks the role of the doctor as the central professional.

Domestic health guides were a significant part of the cultures of health, self-help and mutual aid evident in the late colonial period and early twentieth century in both New Zealand and Australia. We need to understand the history of midwifery in relation to this social context. Examining domestic health guides is an important avenue for achieving this and for enriching our knowledge of midwifery's history. 
The value in considering history relevant to health professions has already been demonstrated in arguments for its inclusion in professional education (e.g. Foureur \& Hunter, 2010; Wood, 2014), and in using historical imagination to consider current professional issues (Wood, 2010). This analysis of information about childbirth in domestic health guides provides an historical example to support reflection on the role of the midwife in relation to lay carers and home birth, and to the place of accessible health information in women's understanding of the childbirth experience today.

\section{ACKNOWLEDGEMENTS AND CONFLICT OF INTEREST STATEMENT}

The authors state there is no identifiable conflict of interest.

\section{REFERENCES}

Black, G. (n.d. c1910). The doctor at home and nurse's guide. London and Melbourne: Ward Lock.

Black, G. (n.d. c1940). The doctor at home and nurse's guide. London and Melbourne: Ward Lock.

'Books wanted'. (1927). Auckland Star (20 September), 7.

Brookes, B. (2003). Hygiene, health, and bodily knowledge, 1880-1940: A New Zealand case study. Journal of Family History, 28, 297-313.

Clarke, A. (2012). Born to a changing world: Childbirth in nineteenthcentury New Zealand. Wellington: Bridget Williams Books.

Coleborne, C., \& Godtschalk, O. (2013). Colonial families and cultures of health: Glimpses of illness and domestic medicine in private records in New Zealand and Australia, 1850-1910. Journal of Family History, 38, 403-421.

Corkill, T. F. (1940). Lectures on midwifery and infant care: A New Zealand course (2nd ed.). Christchurch: Whitcombe \& Tombs.

Corkill, T. F. (1946). Lectures on midwifery and infant care: A New Zealand course (3rd ed.). Christchurch: Whitcombe \& Tombs.

Foureur, M, \& Hunter, M. (2010). The place of birth. In S. Pairman, S. Tracy, C. Thorogood, \& J. Pincombe (Eds.), Midwifery: Preparation for practice (pp.104-123). Marrickville, NSW: Churchill Livingstone.

Gilkison, A., Giddings, L. S., \& Smythe, L. (2013). The shaping of midwifery education in Aotearoa, New Zealand. New Zealand College of Midwives Journal, 47, 18-23.

Grehan, M. (2004). 'From the sphere of Sara Gampism': The professionalisation of nursing and midwifery in the Colony of Victoria. Nursing Inquiry 11(3), 192-201.

Hatrick, C. D. (n.d. c1945). The doctor at home and nurse's guide. London and Melbourne: Ward Lock.

Illustrated family doctor (by a general practitioner) [The]. (1935). London: Home Entertainment Library.

James, W. H. (1923). Home nursing and ailments of children: A handbook for mothers. Warburton, VIC: Signs Publishing.

James, W. H. (1929). Home nursing and ailments of children: A handbook for mothers (6th ed.). Signs Publishing, Warburton, 1929.

Jellett, H. (1926). A short history of midwifery for nurses (7th ed.).

London: J. \& A. Churchill.

Jellett, H. (1929). A short history of midwifery for nurses (8th ed). London: J. \& A. Churchill.

Kirk, E. B. (1904). Papers on health by Professor Kirk Edinburgh (2nd ed.). London: Simpkin Marshall Hamilton Kent.

Kirk, E.B. (1930). Papers on health by Professor Kirk Edinburgh (3rd ed.). London: Simpkin Marshall.

Lewenson, S., \& Hermann, E. (Eds.) (2007). Capturing nursing history: A guide to historical methods in research. New York: Springer.

Macdonald, C. (2011). Strong, beautiful, and modern: National fitness in Britain, New Zealand, Australia, and Canada, 1935-1960. Wellington: Bridget Williams Books.

Mein Smith, P. (1986). Maternity in dispute: New Zealand 1920-1939.

Wellington: Government Printer.

Mortimer, B., \& McGann, S. (Eds.). (2005). New directions in the history of nursing. London: Routledge.
Motherhood book [The]. (n.d. c1920s). London: Amalgamated Press. Muskett, P. E. (1903). Illustrated medical guide, New Zealand edition. Wellington: Williams \& Brooks.

Pairman, S. (2005). From autonomy and back again: Educating midwives across a century, Part 1. New Zealand College of Midwives Journal, 33, 4-9.

Pearn, J. (2012). 'Where there is no doctor': Self-help and pre-hospital care in colonial Australia. Health \& History, 14(2), 162-180.

Raftery, J. (1999). Keeping healthy in nineteenth-century Australia. Health \& History 1(4), 274-297.

Richards, F.C., \& Richards, E.S. (n.d. c1910). Ladies' handbook of home treatment. Melbourne: Signs Publishing.

Richards, E. S. (1945). Ladies' handbook of home treatment. Melbourne: Signs Publishing.

Rossiter, F. M. (1910). The practical guide to health. Melbourne: Signs Publishing.

Rossiter, F. M. (1913). The practical guide to health. Melbourne: Signs Publishing.

Somerville, G. (Ed.) (n.d. c1920s). Newnes family health encyclopaedia. London: Carlton House.

Tosh, J. (2015). The pursuit of history: Aims, methods and new directions in the study of history (6th ed.). London: Routledge.

Wood, P. J. (2010). Historical imagination and issues in rural and remote area nursing. Australian Journal of Advanced Nursing, 27(4), 54-61.

Wood, P. J. (2011). Understanding and evaluating historical sources in nursing history research. Nursing Praxis in New Zealand, 27(1), 25-33.

Wood, P. J. (2013). The blurred boundary between professional and lay home nursing knowledge and practice in New Zealand, 1900-1935. Home Healthcare Nurse, 31 (2), E1-E7.

Wood, P.J. (2014). Historical imagination, narrative learning and nursing practice: Graduate nursing students' reader-responses to a nurse's storytelling from the past. Nurse Education in Practice, 14(5), 473-478.

Wood, P. J., \& Foureur, M. (2005). Exploring the New Zealand maternity archive of the St Helens Hospital, Wellington, New Zealand, 1907-22: An historian and midwife collaborate. In B. Mortimer \& S. McGann (Eds.), New directions in the history of nursing (pp.179-193). London: Routledge.

Wood, P. J., \& Foureur, M. (2007). A clean front passage: Dirt, douches and disinfectants at St Helens Hospital, Wellington, New Zealand, 1907-1922. In M. Kirkham (Ed.) Exploring the dirty side of women's health (pp.30-43). London: Routledge.

Unless noted, all quotations from Muskett (1903) are from volume 2.

\section{Accepted for publication October 2015}

Wood, P., \& Jones, J. (2015). Health guides for unattended births and aftercare in New Zealand and Australia, 1900-1950. New Zealand College of Midwives Journal 51, 44-49. http://dx.doi.org/10.12784/ nzcomjnl51.2015.7.44-49 